\title{
El nou paradigma docent i la problemàtica de la implantació a les escoles d'empresarials d'acord amb el Pla Bolonya Els estudis a les empreses, cobreixen les expectatives dels empresaris? ${ }^{1}$
}

\author{
Núria Rodríguez Ávila \\ Universitat de Barcelona. Departament de Sociologia i Anàlisi de les Organitzacions \\ nrodriguez@ub.edu
}

\section{Teresa Monllau Jaques}

Universitat Pompeu Fabra. Departament d'Economia i Empresa

teresa.monllau@upf.edu

Recibido: 28-05-2007

Aceptado: 28-01-2009

\section{Resum}

El projecte Tunning sobre educació superior a Europa centra les seves accions, entre d'altres, a definir competències genèriques (instrumentals, interpersonals i sistèmiques) i competències específiques (saber concret d'un àmbit acadèmic). Les ciències socials es plantegen el repte d'adaptar aquest procés a unes certes mancances, perquè el servei que presta al mercat de treball no és tangible i està fet a mida. L'objectiu que persegueix és identificar les competències que, segons els docents, els empresaris i altres agents socials, han d'haver assolit els alumnes. Per realitzar el treball de camp, hem pres com a referència els professors i els empresaris relacionats amb la diplomatura de Ciències Empresarials de la Universitat Pompeu Fabra durant el curs 2005-2006.

Paraules clau: sociologia de les professions, escoles d'empresarials, economistes, professions socials.

Abstract. The new teaching paradigm and the problem of introducing the Bolonia Plan in bussiness schools

The Tunning project on higher education focuses, among other issues, on the definition of generic (instrumental, interpersonal, and systemic) as well as specific competences. Social sciences face the challenge of adapting this process to the existence of some shortcomings in their usefulness for labour markets. The aim of the project is to identify competences that students should achieve, according to teachers, employers, and other social agents. The field work presented in this article focuses on teachers and employers related to the studies of Bussiness Sciences of the Universitat Pompeu Fabra during the academic year 2005-2006.

Key words: sociology of the professions, business schools, economists, social professions.

1. Agräm a Carme Hernández, del Centre per a la Qualitat i la Innovació Docent de la Universitat Pompeu Fabra i experta en pedagogia, els comentaris que ha fet per millorar l'article. 


\section{Sumari}

Introducció 2. Elements nous dins dels perfils profes-

1. Aproximació teòrica a la sociologia sionals: cas de les escoles d'empresarials

de les professions

Conclusions

Bibliografia

\section{Introducció}

El marc teòric d'aquest treball se situa en el camp de la sociologia de les professions. En concret, pretén analitzar si l'orientació metodològica utilitzada en l'àmbit de l'educació superior cobreix les demandes de l'entorn econòmic i professional.

D'altra banda, volem veure si el que fem els professors universitaris serveix per col-locar els futurs professionals. Efectivament, el mercat de treball actual es caracteritza perquè sofreix canvis ràpids, tant pel que es refereix a tècniques com a localitzacions. És necessari que els nous titulats acabin els estudis amb unes competències i amb unes capacitats que els permetin d'adaptar-se a l'entorn contínuament variable.

\section{Aproximació teòrica a la sociologia de les professions}

El segle XX va ser considerat el de les professions, perquè va ser en la societat industrial on aquestes es van configurar i es van detectar. Ara bé, serà el desenvolupament de la societat de serveis la que en provocarà un increment considerable (Goode, 1960). Tanmateix, també té lloc un augment del nombre d'ocupacions que intenten adquirir els símbols d'estatus de les professions i que es considera que són semiprofessions o que estan en procés de professionalització.

El segle XXI és el de la societat del coneixement i les noves tecnologies. És l'època en què estan tenint lloc grans canvis en el món de la comunicació i l'estructura del mercat laboral, caracteritzada per una globalització creixent, $i$ on es posa de manifest la necessitat de professionals que tinguin capacitats $i$ competències més adients amb els canvis del mercat de treball.

\subsection{Escoles de pensament principals al voltant de les professions}

Existeixen tres escoles de pensament. Són les següents:

\subsubsection{Escola definidora}

Els elements que treballa l'escola definidora són els atributs i les diferències entre professions. Els autors principals d'aquest corrent de pensament són: Spencer, Marshall, Carr-Saunders i Wilson. Les característiques indispensables per definir les professions són: la possessió i la transmissió de coneixements; el fet de constituir un bé per a la comunitat; la realització del control intern; uns col-legis professionals, $\mathrm{i}$, per últim, un sistema de premis com a símbol de la millora i la superació. 


\subsubsection{Escola evolutiva}

L'escola evolutiva parteix del procés de professionalització. Fa una anàlisi de quines són les etapes per arribar a la consideració de professió clàssica. Els principals autors són, entre d'altres: Parson, Moore, Wilensky, Greenwood, Barber, Goode i Etzioni. Consideren que existeixen atributs estructurals, com ara treball a temps complet, activitat independent, col-legis professionals, monopoli de la pràctica i exercici professional. També hi ha atributs ideològics, com ara: la idea de ser un col-lectiu elemental en el treball a nivell social, la creença (entesa com a servei públic per a la comunitat de caràcter indispensable), l'autoregulació (basada en el fet que són els propis professionals els qui poden controlar la seva pròpia feina), la idea de dedicació exclusiva i l'autonomia (entesa com a creença que són els propis professionals els qui han de prendre les decisions sobre la seva activitat laboral).

\subsubsection{Escola revisionista}

L'escola revisionista té una visió crítica dels corrents de pensament anterior. El seu paradigma analitza les professions sota l'enfocament de sistemes i examina relacions entre professions. Els autors més representatius són, entre d'altres: Ben-David, Freidson, Hughes, Illich i Johnson. Consideren que els atributs dels professionals serveixen per augmentar el poder que tenen en el mercat laboral. Ivan Illich, al seu llibre Profesiones inhabilitantes (1981), hi observa com els experts s'apropien de certes àrees i adopten unes conductes determinades, de manera que, mitjançant l'exercici de les seves professions, es generen problemes nous que garanteixen la seva existència. És llavors quan es passa de l'aprovació a la desaprovació dels professionals (Ilich, 1981).

\subsection{El sistema de professions}

Segons Andrew Abbott, existeix un sistema de professions. Cadascuna pot estendre la seva jurisdicció o àrea de treball de manera limitada. El seu model és una professió per una jurisdicció. També cada vacant en el model de professions és igual al moviment de professions. Per a Abbott, existeixen forces externes que obren i tanquen jurisdiccions d'una professió. Els canvis es propaguen en cadena pel sistema de professions. Les forces externes de canvi del sistema són principalment la tecnologia, les modificacions en les organitzacions, fets naturals i culturals. D'altra banda, les forces internes de canvi de jurisdicció desenvolupen coneixements i perícies nous (Abbott, 1988).

\subsection{Situació actual de les professions}

Les universitats són la font del coneixement abstracte per a les professions. El nou escenari que planteja Bolonya comporta un procés de definició dels futurs professionals. Això generarà un nou mapa de professions on el mercat proposarà les prioritats de la nova configuració laboral. També servirà per establir la 
formació continuada al llarg de la vida com a eina clau. A continuació, explicarem aquest escenari en el cas del nou grau d'empresarials.

\section{Elements nous dins dels perfils professionals: cas de les escoles d'empresarials}

L'Espai Europeu d'Ensenyament Superior (EEES) comporta que els diferents treballs que tenen com a objecte el coneixement i l'estudi del món empresarial $^{2}$ necessitin plantejar-se una metodologia que cobreixi les necessitats de l'entorn social, econòmic i professional. La conseqüència immediata és el replantejament del procés de formació empresarial en el context de la nova societat del coneixement.

Durant l'estiu de l'any 2000, un grup d'universitats va acceptar col-lectivament el repte formulat a Bolonya i va elaborar un projecte pilot anomenat Tunning. Sintonitzar les estructures educatives d'Europa, més conegut per projecte Tunning. Aquest document és el que té més impacte dels creats per les universitats europees per respondre al repte de la Declaració de Bolonya i el Comunicat de Praga.

La importància d'aquest document rau en el fet que es preocupa d'analitzar diferents línies d'acció assenyalades a Bolonya i, particularment, l'adopció d'un sistema de titulacions que es pugui reconèixer $i$ comparar amb facilitat.

Les línies d'acció que s'han seguit i que se segueixen durant el procés són:

1. Definició de competències genèriques.

2. Definició de competències específiques.

3. El paper del sistema ECTS com a sistema d'acumulació.

4. Funció de l'aprenentatge, la docència, l'avaluació i el rendiment en relació amb la qualitat de l'ensenyament.

Molts dels centres que estudien l'àmbit empresarial estan realitzant un procés d'adaptació a Bolonya. El present treball analitzarà, d'una banda, si els objectius, quant a formació de personal, que tenen els estudis centrats en el món de l'empresa coincideixen amb la demanda que els fan des de l'àmbit laboral. D'altra banda, analitzarà si la metodologia docent seguida durant els estudis és adequada per cobrir les necessitats empresarials.

\subsection{Objectius}

En concret, el present treball té com a objectius:

- Identificar les competències que, segons els professors, els empresaris i altres agents socials, han d'haver assolit els alumnes en finalitzar els estudis.

2. Ens estem referint a estudis que reben noms diversos, com ara Empresarials o Direcció i Administració d'Empreses. 
- Analitzar si la metodologia i el sistema d'avaluació que utilitzen els professors són els adequats per assolir les competències definides.

- Veure quina és la problemàtica que es fa palesa quan s'aplica el nou paradigma docent i les capacitats d'innovació que té.

\subsection{Descripció del treball de camp}

L'estudi que presentem és el cas sobre l'Escola de Ciències Empresarials de la Universitat Pompeu Fabra. La metodologia utilitzada ha estat tant quantitativa com qualitativa.

La investigació quantitativa és útil quan es tracta de veure la freqüència amb què es produeix un fet, o bé si se'n vol obtenir una idea general sense perdre'n gaire informació (Kirk y Miller, 1990. Aquest tipus d'anàlisi és adequat quan es vol obtenir una primera descripció de la població i de l'heterogeneïtat que la caracteritza. Hem utilitzat aquesta tècnica per definir les competències que, des del punt de vista dels diferents agents socials, és important que hagin assolit els diplomats en Ciències Empresarials.

La investigació qualitativa és útil quan es tracta d'analitzar la classe, l'exactitud, la rellevància i la riquesa de les dades derivades de la mostra. Una part del nostre estudi s'ha basat en metodologia qualitativa, ja que és més important comprendre les percepcions i el comportament de l'entrevistat que no pas mesurar l'extensió amb què es produeixen els fets.

Per realitzar el treball, hem dissenyat dos tipus de qüestionaris: un per a professors de les assignatures relacionades d'organitzacions d'empreses i empresaris, i un altre per a la resta de professorat.

El punt de partida de la nostra investigació ha estat la identificació de les competències que han d'haver assolit els alumnes al final dels seus estudis.

La definició de competències és un aspecte bàsic, ja que comporta, entre d'altres, els avantatges següents (González i Wagenaar (ed.), 2003):

1. Fomenta la transparència entre els perfils professionals i acadèmics de les titulacions i dels programes d'estudi, a més a més, afavoreix remarcar la importància dels resultats obtinguts.

2. Desenvolupa el nou paradigma docent centrat en l'estudiant i en les necessitats de dirigir-se cap a la gestió del coneixement.

3. Satisfa les demandes d'una societat d'aprenentatge creixent i d'una flexibilitat més gran en l'organització d'aquest aprenentatge.

4. Dóna un impuls a la dimensió europea d'educació superior.

5. Proporciona un llenguatge més adient per facilitar l'intercanvi.

Per definir les competències que han d'assolir els estudiants objecte d'estudi, ens hem centrat en dues poblacions: els empresaris que contracten alumnes en pràctiques i els professors de l'àrea d'organització d'empreses.

Les empreses que contracten els alumnes analitzats són PIME; no són freqüents els grups d'empreses. També hi tenen un pes important les que perta- 
Taula 1. Forma jurídica de les empreses amb convenis UPF

\begin{tabular}{lr}
\hline Característiques empresarials & $\%$ \\
\hline Societats anònimes & 31 \\
Societats de responsabilitat limitada & 49 \\
Bancs i caixes & 20 \\
& $100(N=38)$ \\
\hline
\end{tabular}

Font: Oficina d'Inserció Laboral (OIL). Universitat Pompeu Fabra.

nyen al sector de la banca. La taula 1 recull un resum de la forma jurídica de les empreses que tenen convenis amb la nostra universitat.

Per realitzar l'estudi, la població de referència ha estat la totalitat d'empresaris que han contractat els nostres alumnes en pràctiques durant el període que va de gener a juny de 2006, i que l'estudiant que ha realitzat la pràctica hagi sol-licitat el reconeixement de crèdits.

El qüestionari que es va facilitar als empresaris estava centrat en la definició de les habilitats d'un diplomat en Ciències Empresarials, amb un total de vint-i-nou habilitats.

Per analitzar la coherència existent entre el tipus de metodologia docent $\mathrm{i}$ les competències que es pretenien assolir, ens vàrem centrar en la població dels professors que han impartit assignatures als estudiants durant el primer i el segon trimestres. Les respostes que vàrem analitzar són les referides a la metodologia, la motivació, l'avaluació i les competències que calia desenvolupar.

Per analitzar la problemàtica i els avantatges del nou model docent, vàrem utilitzar com a metodologia de referència la realització d'entrevistes en profunditat.

\subsection{Les competències dels diplomats en Ciències Empresarials}

Per identificar les competències que ha d'haver assolit un diplomat en Ciències Empresarials, n'hem analitzat els aspectes següents:

1. Les competències més valorades per empresaris i professors.

2. Les divergències d'opinió que s'han pogut detectar entre empresaris i professors a l'hora de determinar la importància de les competències.

3. Aspectes que ens han cridat l'atenció en els resultats obtinguts

\subsubsection{Competències més valorades}

Les competències més valorades per empresaris i professors han estat:

1. La capacitat d'aplicar els coneixements a la pràctica.

2. La capacitat d'aprenentatge.

3. Les habilitats de gestió de la informació.

4. El treball en equip.

5. La iniciativa i l'esperit emprenedor.

6. El compromís ètic. 
Taula 2. Capacitat d'aplicar els coneixements a la pràctica (percentatges).

\begin{tabular}{lccc}
\hline Capacitat & Empresaris & Prof. org. d'empreses & Total \\
\hline Elevat & 42,1 & 64,3 & 48,0 \\
Bastant & 44,7 & 21,4 & 38,5 \\
Escàs & 7,9 & 14,3 & 9,6 \\
Nul & 5,3 & - & 3,8 \\
& $100(N=38)$ & $100(N=14)$ & $100(N=52)$ \\
\hline
\end{tabular}

Font: elaboració pròpia a partir de l'estudi Les escoles d'empresarials davant Bolonya: el nou paradigma docent $i$ la problemàtica de la implantació (2006).

Analitzem el contingut i el resultat obtingut en cadascuna d'aquestes competències.

La capacitat d'aplicar coneixements a la pràctica fa referència a la facilitat que mostra l'alumne, futur professional, a l'hora d'aplicar el marc conceptual a problemes reals. Els resultats obtinguts han estat els que es mostren a la taula 2. Crida l'atenció el fet que la importància que els professors assignen a aquesta capacitat és molt superior a l'assignada pels empresaris. El professor mostra preocupació per transmetre la utilitat pràctica de la seva assignatura.

Quan es parla de la capacitat d'aprenentatge com a competència, es fa referència a la capacitat que té l'alumne, futur professional, d'identificar aquells elements que són comuns i diferents de situacions viscudes amb anterioritat. Els resultats obtinguts respecte a aquesta habilitat es troben a la taula $3 \mathrm{i}$ assenyalen dues coses: en primer lloc, que hi ha acord entre empresaris i professors a l'hora de valorar la capacitat d'aprenentatge; en segon lloc, i comparant els resultats amb els obtinguts en la resta de capacitats, veiem que aquesta és la que es considera més important.

L'habilitat de la gestió de la informació fa referència a la capacitat que té l'alumne, futur professional, de saber utilitzar o rebutjar les diferents fonts d'informació a l'hora d'analitzar una situació o de resoldre un problema. Els resultats obtinguts respecte d'aquesta habilitat es troben a la taula 4 . Des del nostre punt de vista, crida l'atenció el fet que no es tracta de les competències més

Taula 3. Capacitat d'aprenentatge (percentatges)

\begin{tabular}{lccc}
\hline Capacitat d'aprenentatge & Empresaris & Prof. org. d'empreses & Total \\
\hline Elevat & 68,4 & 71,4 & 69,2 \\
Bastant & 21,1 & 21,4 & 21,2 \\
Escàs & 5,3 & 7,1 & 5,8 \\
Nul & 5,3 & - & 3,8 \\
& $100(N=38)$ & $100(N=14)$ & $100(N=52)$ \\
\hline
\end{tabular}

Font: elaboració pròpia a partir de l'estudi Les escoles d'empresarials davant Bolonya: el nou paradigma docent i la problemàtica de la implantació (2006). 
Taula 4. Habilitats de gestió de la informació (percentatges)

\begin{tabular}{lccc}
\hline $\begin{array}{l}\text { Habilitats de gestió } \\
\text { de la informació }\end{array}$ & Empresaris & Prof. org. d'empreses & Total \\
\hline Elevat & 37,8 & 57,1 & 43,1 \\
Bastant & 45,9 & 35,7 & 43,1 \\
Escàs & 13,5 & 7,1 & 11,8 \\
Nul & 2,7 & - & 2,0 \\
& $100(N=38)$ & $100(N=14)$ & $100(N=52)$ \\
\hline
\end{tabular}

Font: elaboració pròpia a partir de l'estudi Les escoles d'empresarials davant Bolonya: el nou paradigma docent $i$ la problemàtica de la implantació (2006).

Taula 5. Treball en equip (percentatges)

\begin{tabular}{lccc}
\hline Treball en equip & Empresaris & Prof. org. d'empreses & Total \\
\hline Elevat & 55,5 & 78,6 & 61,5 \\
Bastant & 23,7 & 14,3 & 21,2 \\
Escàs & 13,2 & 7,1 & 11,5 \\
Nul & 7,9 & - & 5,8 \\
& $100(N=38)$ & $100(N=14)$ & $100(N=52)$ \\
\hline
\end{tabular}

Font: elaboració pròpia a partir de l'estudi Les escoles d'empresarials davant Bolonya: el nou paradigma docent $i$ la problemàtica de la implantació (2006).

valorades, ja que tan sols un $43,1 \%$ de la població enquestada la considera molt important.

El treball en equip indica la capacitat que té l'alumne professional de treballar en un grup format per persones amb diferents tarannàs i qualitats. Segons la taula 5, es conclou que es tracta d'una competència molt valorada, tant per empresaris com per docents, però que aquests últims li confereixen més importància.

La iniciativa i l'esperit emprenedor fan referència a la capacitat que mostra l'estudiant, futur professional, per crear situacions noves. Els resultats obtinguts es troben a la taula 6 . En aquest cas, esperàvem que aquesta fos una competència més valorada per empresaris que no pas per professors, però els resultats obtinguts han estat ben diferents de les nostres expectatives. L'explicació pot raure en el fet que l'empresari de la PIME ja té iniciativa i esperit emprenedor, i el que busca a l'hora de contractar un diplomat és un professional amb una base conceptual forta.

Una de les competències més valorades per empresaris a la qual els professors no donen tanta importància és el compromís ètic. Quan s'avalua aquesta capacitat, s'està fent referència a la responsabilitat social que té l'alumne, futur professional. Els resultats obtinguts en aquesta competència es troben resumits a la taula 7 . El percentatge d'empresaris que han donat una importància elevada a aquesta competència està per sobre del percentatge de professors. Aquesta diferència d'opinió pot venir provocada pel fet que el professor entén 
Taula 6. Iniciativa i esperit emprenedor segons empresaris i professors d'organitzacions d'empreses (percentatges)

\begin{tabular}{lccc}
\hline $\begin{array}{l}\text { Iniciativa } \mathbf{i} \\
\text { esperit emprenedor }\end{array}$ & Empresaris & $\begin{array}{c}\text { Prof. organitzacions } \\
\text { d'empreses }\end{array}$ & Total \\
\hline Elevat & 52,6 & 71,4 & 57,7 \\
Bastant & 23,7 & 21,4 & 23,1 \\
Escàs & 21,1 & - & 15,4 \\
Nul & 2,6 & 7,1 & 3,8 \\
& $100(N=38)$ & $100(N=14)$ & $100(N=52)$ \\
\hline
\end{tabular}

Font: elaboració pròpia a partir de l'estudi Les escoles d'empresarials davant Bolonya: el nou paradigma docent $i$ la problemàtica de la implantació (2006).

Taula 7. Compromís ètic segons empresaris i professors d'organitzacions d'empreses (percentatges)

\begin{tabular}{lccc}
\hline Compromís ètic & Empresaris & $\begin{array}{l}\text { Prof. organitzacions } \\
\text { d'empreses }\end{array}$ & Total \\
\hline Elevat & 58,3 & 57,1 & 58,0 \\
Bastant & 27,8 & 28,6 & 28,0 \\
Escàs & 8,3 & 14,3 & 10,0 \\
Nul & 5,6 & - & 4,0 \\
& $100(N=38)$ & $100(N=14)$ & $100(N=52)$ \\
\hline
\end{tabular}

Font: elaboració pròpia a partir de l'estudi Les escoles d'empresarials davant Bolonya: el nou paradigma docent i la problemàtica de la implantació (2006).

que la seva funció principal és ensenyar a l'alumne, formar-lo. Les repercussions que pot tenir per al professor el compromís ètic de l'alumne són molt petites. Per a l'empresari, el fet que el professional que treballa a la seva empresa sigui poc responsable socialment, pot tenir repercussions d'imatge de marca, econòmiques, etc.

\section{Competències menys valorades}

En analitzar les habilitats menys valorades per empresaris i professors, veiem que són les que tenen a veure amb la diversitat cultural i el coneixement d'altres cultures. El 60\% dels enquestats atribueix una importància escassa al coneixement de cultures i costums d'altres països; un $72 \%$ dels enquestats considera entre bastant valorada i escassament valorada la capacitat de donar importància a la diversitat i a la multiculturalitat. Aquest resultat pot ser consequiència del fet que les empreses que contracten els nostres alumnes tenen poca projecció internacional.

\section{Competències amb divergència}

En analitzar els resultats obtinguts en les competències, n'hem observat un conjunt que, tot i ser importants, el grau d'importància que els confereixen els empresaris difereix del dels professors. Aquestes competències són: 
1. La capacitat d'anàlisi i de síntesi, que està considerada molt important pels professors $(71,4 \%) \mathrm{i}$ tan sols bastant important pels empresaris $(47,4 \%)$. La divergència que existeix entre empresaris i professors l'atribuïm al fet que un diplomat poques vegades serà contractat per ocupar un càrrec directiu, sinó que més aviat se li assignaran tasques que tinguin poc marge de decisió.

2. El coneixement de la pròpia llengua i d'altres llengües és sempre més valorat pels professors que no pas pels empresaris. Per exemple, tan sols el 44,7\% dels empresaris enquestats considera que la comunicació oral i escrita en la pròpia llengua és una competència molt important, i tan sols un 19,4\% dels empresaris enquestats considera que el coneixement d'una segona llengua és una capacitat molt important. Probablement, el resultat obtingut en aquestes capacitats té a veure amb la limitada projecció internacional de les empreses que contracten els nostres estudiants.

3. Les habilitats informàtiques bàsiques estan valorades com a molt importants pels empresaris $(72,7 \%)$ i com a bastant importants pels professors $(57,1 \%)$. La divergència obtinguda la considerem lògica, ja que, en una empresa, l'eina bàsica de treball és l'ordinador, però aquest aspecte no és tan important a l'hora d'impartir una assignatura.

4. La capacitat per adaptar-se a situacions noves està més ben valorada per professors que no pas per empresaris. Un 78,6\% dels professors enquestats la considera molt important, mentre que tan sols la troba molt important el 36,4\% dels empresaris. Possiblement, el resultat obtingut en aquesta competència té a veure amb els llocs que ocupen els nostres estudiants en l'organigrama de l'empresa.

\section{Altres resultats}

Dels resultats obtinguts, crida especialment l'atenció que:

1. L'habilitat de recerca i la capacitat crítica i autocrítica, que s'esperava que fos considerada molt important, tan sols és considerada bastant important.

2. La capacitat de generar idees noves està més valorada pels professors (un $64,3 \%$ dels enquestats la considera molt important), que no pas pels empresaris (un 18\% dels empresaris la considera molt important). Aquest resultat és coherent amb l'obtingut amb la competència que fa referència a la iniciativa i a l'esperit innovador, i probablement té a veure amb la poca competitivitat que s'atribueix a l'empresa espanyola.

3. La resolució de problemes està menys valorada pels empresaris que no pas pels professors. Un cop més, la feina per la qual són contractats els nostres alumnes té a veure amb el resultat obtingut en analitzar-ne la capacitat.

4. L'interès per la qualitat està molt més valorat pels empresaris que no pas pels professors. Un $81,8 \%$ dels empresaris enquestats el considera molt important, mentre que tan sols és considerat molt important pel $42,9 \%$ dels professors. 
Taula 8. Manera d'incentivar la participació de l'alumnat

\begin{tabular}{lc}
\hline Preguntes & $27,1 \%$ \\
Exercicis & $18,8 \%$ \\
Casos & $10,4 \%$ \\
Altres & $18,8 \%$ \\
No contesta & $24,9 \%$ \\
& 100 \\
\hline
\end{tabular}

Font: elaboració pròpia a partir de l'estudi Les escoles d'empresarials davant Bolonya: el nou paradigma docent $i$ la problemàtica de la implantació (2006).

Un cop definides les competències, vam analitzar la metodologia, els sistemes d'avaluació utilitzats i les competències que han d'haver assolit els alumnes en el transcurs de l'assignatura.

Si analitzem la metodologia seguida per la població analitzada, veiem que un $87,5 \%$ dels enquestats diu que la classe magistral és el primer mètode utilitzat a l'hora d'impartir l'assignatura. Unes altres metodologies utilitzades bàsicament per professors que imparteixen assignatures de dret, organització d'empresa i comptabilitat són la resolució de casos, la realització de simulacions i la realització de projectes. Aquesta metodologia és coherent amb la manera d'incentivar la participació de l'alumnat a l'aula. Els resultats obtinguts es troben resumits a la taula $8 \mathrm{i}$ indiquen que el $45,9 \%$ de la població entrevistada utilitza les preguntes i la realització d'exercicis per aconseguir-ho.

Les maneres d'avaluar el rendiment de l'estudiant són: l'examen final, la realització de pràctiques, la realització de parcials i les presentacions orals; ara bé, la variable que té més pes en la nota definitiva és l'examen final: un $75 \%$ dels professors enquestats li atorguen un pes superior o igual al 50\%.

\section{Avantatges i problemes de la implantació del nou paradigma docent}

Quan parlem dels avantatges i dels inconvenients de la implantació del nou sistema, hem de remarcar que hi ha pocs professors que l'hagin adaptat; en concret, tan sols un 8,6\%. Els motius són els següents:

1. Hi ha molts dubtes sobre la futura continuïtat dels estudis d'Empresarials. Existeix una gran convicció que seran absorbits pels estudis en Administració i Direcció d'Empreses. Aquest fet, unit amb la gran proporció d'associats que té l'escola (un $62 \%$ del professorat), i que veu perillar la seva continuïtat, fa que no hi hagi gaire motivació per adaptar-se al nou sistema.

2. El nou sistema comporta molta feina que no sempre és valorada per l'entorn del professor. El docent té la sensació que, a l'hora de valorar el seu currículum, hi ha uns altres factors que es consideraran més importants, com ara, per exemple, la tasca investigadora. D'altra banda, molts dels alumnes consideren que el nou sistema no els aporta millores i ofereixen una certa resistència a la implantació de les noves metodologies.

La nova metodologia docent se centra a reduir el nombre d'hores destinades a la classe magistral i a incrementar el temps que l'estudiant ha de dedicar 
Taula 9. El rendiment dels alumnes

\begin{tabular}{lcc}
\hline & Semipresencial & Presencial \\
\hline Presentats & 97,4 & 84,53 \\
No presentats & 2,6 & 15,47 \\
Anul.len convocatòria & 1,29 & 6,18 \\
No presentats & 1,29 & 9,27 \\
Superen l'examen & 93,33 & 85,36 \\
No superen l'examen Examen & 6,76 & 14,64 \\
\hline
\end{tabular}

a estudiar i a treballar l'assignatura. Els sistemes utilitzats per assolir aquesta fita són diversos. Hi ha professors, la gran majoria, que fan que part de les hores previstes en el calendari docent de l'assignatura sigui destinada a la realització de seminaris o, el que és el mateix: l'alumne treballa a l'aula, o bé de forma individual o bé en grups, a partir de la tasca que li proposa el professor. Un altre sistema és reduir el temps de presencialitat a l'aula i incrementar el que es destina a la tutorització de l'alumne.

Els avantatges que presenta el sistema nou són els següents:

1. Hi ha una comunicació i una retroacció més gran amb l'alumne.

2. El rendiment dels alumnes augmenta, tal com es pot veure a la taula 9.

3. Davant el procés d'aprenentatge, l'actitud de l'estudiant és molt més activa i creativa.

Quan n'hem analitzat els inconvenients, els resultats obtinguts han estat els següents: no solament hem tingut en compte l'opinió dels professors, sinó també la del personal administratiu:

1. La tendència a reduir la dimensió del grup provoca problemes d'espai i d'horaris que no sempre és compatible amb l'horari alternatiu de matí o de tarda que, en l'actualitat, tenim als estudis.

2. El nou sistema comporta molta més feina, que no sempre és valorada ni des del punt de vista curricular, ni pel que fa a crèdits reconeguts que imparteix el professor.

3. Valoració que fan els alumnes del nou sistema. En aquest punt, hem pogut detectar dos grups de professors: d'una banda, els que afirmen que la valoració realitzada pels alumnes és altament positiva i, de l'altra, els que diferencien dos grups d'alumnes molt marcats: aquell que aplaudeix la iniciativa i aquell altre que percep el sistema com una forta forma de control.

Volem remarcar que, malgrat tots els inconvenients, la totalitat dels professors entrevistats considera que el nou sistema és molt positiu i afirma que cal treballar per implantar-lo. 


\section{Conclusions}

La sociologia de les professions es planteja les professions amb els elements definidors, evolutius i diferenciadors. Però el nou paradigma de les professions i dels perfils professionals parteix de les competències estructurals, interpersonals i sistèmiques.

Quan es tracta de definir les competències, es detecta divergència entre el que vol l'empresari i el que el professor creu que vol l'empresari. Aquesta divergència planteja la necessitat d'incrementar la comunicació entre el món empresarial i el món universitari.

L'empresari vol una persona que tingui interès per la qualitat $(81,8 \%)$, amb un compromís ètic elevat $(81,8 \%)$, que tingui capacitat d'aprenentatge $(72,7 \%)$, que sàpiga aplicar els coneixements a la pràctica $(72,7 \%)$, que tingui habilitats informàtiques $(72,7 \%)$ i que sàpiga treballar de manera autònoma $(63,6 \%)$.

El professor vol una persona capaç de treballar en equip $(78,6 \%)$, que sigui capaç d'adaptar-se a situacions noves $(78,6 \%)$, que tingui capacitat d'aprenentatge $(71,4 \%)$, d'anàlisi i de síntesi $(71,4 \%)$ i esperit emprenedor $(71,4 \%)$, que sàpiga aplicar els coneixements a la pràctica $(64,3 \%)$, que sigui capaç de generar idees noves $(64,3 \%)$ i que tingui capacitat de resoldre problemes $(61,5 \%)$.

La conclusió a què arribem després d'analitzar aquest resultat és que estem lluny de l'aplicació de la nova metodologia docent. Les classes magistrals i l'examen final tenen un pes fonamental com a sistema metodològic i com a sistema de valoració.

La metodologia docent i el sistema d'avaluació que estan seguint els professors és allunyada de la filosofia que hi ha darrere del nou paradigma docent: «ensenyar a aprendre». Però aquesta situació és difícil de solucionar si, d'una banda, no es valora la tasca del docent $i$, de l'altra, no s'injecten recursos per tal que el nou sistema pugui ser implementat.

\section{Bibliografia}

Аввотт (1988). A The System of Professions. Chicago: Chicago University Press, capítols 1 y 4 .

Agresti, A. (1990). Categorical data analysis. Nova York: John Wiley.

BENITO, A. i CrUZ, A. (2005). Nuevas claves para la docencia universitaria. En el Espacio Europeo de Educación Superior. Madrid: Narcea.

BRoOKFIELD, S. i PreSkILL, S. (1999). Discussion as a way of teachig. Tools and Techniques for University Teachers. Buckingham: SRHE and Open University Press.

Burrage, M. i Torstendahl, R. (1990). Professions in theory and history. Londres: Sage.

Clariana, M. (2002). Estil d'ensenyament $i$ aprenentatge. Barcelona: Universitat Autonoma de Barcelona.

Colecchia, A. i Papaconstantinou, G. (1996). «The Evolution of Skills in OECD Countries and the Role of Technology». STI Working Papers 1996/8. París: $\mathrm{OECD} / \mathrm{GD}(96) 183$.

DURKHEIM, Emili (1933). La división del trabajo social. Nova York: Macmilan.

EHRENREICH, B. i EHRENREICH, W. (1990). «The profesional-managerial class». Radical America 2. Estats Units. 
Ehrenreich, B. (1990). Por su propio bien: 150 años de consejos de expertos a las las mujeres. Madrid: Taurus.

Escalona, A. (2005). Actividades para la enseñanza y el aprendizaje de competencias genéricas en el marco del espacio europeo de educación superior. Saragossa: Prensas Universitarias.

FERrER, V. (1994). La metodología didàctica a l'ensenyament universitari. Barcelona: Universitat de Barcelona.

FreIDSON, Elliot (1986). Professionalism powers. Chicago: The University of Chicago Press.

- (1994). Professionalism reborn: Theory, prophecy and policy. Chicago: The University of Chicago Press.

GOLDTHORPE, J. (1982). «On the service class, its formation and future». A: A. GIDDENS i G. MACKENZIE. Social class and the division of labor. Londres: Cambridge University Press.

GonZÁlez, J. i WagenaAR, R. (ed.) (2003). Tuning Educational Structures in Europe. Informe Final. Proyecto Piloto. Fase 1. Bilbao: Universidad de Deusto.

Goode, W. L. (1960). «Encraochment, Charlatanism, and the Emerging Profession». American Sociological Review, núm. 25. Estats Units: ASR.

GOUlDNER, Alvin (1985). El futuro de los intelectuales y el ascenso de la nueva clase. Madrid: Alianza.

GuILLÉN, Mauro (1990). «Profesiones y burocracia, desprofesionalización, proletarización y poder profesional en las organizaciones complejas». REIS, núm. 51. Madrid: CIS, p. 35-51.

Hernandez, F.; Martínez, P.; Dafonseca, P. i Rubio, M. (2005). Aprendizaje, competencias y rendimiento en educación superior. Madrid: La Muralla.

IlLICH, Ivan i altres (1981). Profesiones inhabilitantes. Barcelona: Blume.

IMBERNON, F. i MEDINA, J. L. (2005). Metodologia participativa a l'aula universitària. La participació de l'alumnat. Barcelona: Universitat de Barcelona.

KIRK, J. i MiLleR, M. L. (1990). "Reliability and validity in quantitative research». Qualitative Research Methods Series, vol. 1. Newbury Park. Londres, Nova Delhi: A Sage University Paper.

Krause, E. A. (1996). Death of the guilds: Professions, states and the advace of capitalism, 1930 to present. New Haven: Yale University Press.

Martín Moreno, A. de Miguel (1982). Sociología de las profesiones en España. Madrid: CIS.

MATEO J. i MARTíNEZ, F. (2005). L'avaluació alternativa dels aprenentatges. Barcelona: Universitat de Barcelona.

MCKEACHIE, Wilbert, J. (2006). Teaching tips: strategies, research, and theory for college and university teachers. Boston: Houghton Mifflin Company.

NAVARIDAS, F. (2004). Estrategias didácticas en el aula universitaria. Logronyo: Universitat de la Rioja.

PARSONS, Talcott (1954). Essays in sociological theory. Estados Unidos: Frees Press.

PEDRÓ, F. (dir.) (2004). Els estudiants i els processos d'ensenyament i d'aprenentatge a la universitat amb vista als crèdits ECTS. Barcelona: Universitat Pompeu Fabra.

- (dir.) (2005). La metodologia docent i el crèdit ECTS als estudis de Relacions Laborals $i$ Ciències Empresarials. Barcelona: Universitat Pompeu Fabra.

RodrígueZ, Josep A. i GuILlÉN, Mauro F. (1992). "Organizaciones y profesiones en la sociedad contemporánea». Revista Española de Investigaciones Sociológicas, núm. 59, p. 9-18.

SÁNCHEZ, M. i altres (2003). Sociología de las profesiones: pasado, presente y futuro. Murcia: Diego Marín. 